Review

\title{
T cell Metabolism in Lupus
}

Milena Vukelic ${ }^{1, \dagger}$, Michihito Kono ${ }^{2, \dagger, *}$, George C. Tsokos ${ }^{1, *}$

1 Department of Medicine, Beth Israel Deaconess Medical Center, Harvard Medical School, Boston, MA 02115, USA

2 Department of Rheumatology, Endocrinology and Nephrology, Faculty of Medicine, Hokkaido University, Sapporo 060-0808, Japan

$\dagger$ These two authors contributed equally to this work.

* Correspondence: George C. Tsokos, Email: gtsokos@bidmc.harvard.edu; Tel.: +1-617-735-4160; Michihito Kono, Email: m-kono@hokudai.ac.jp; Tel.: +81-11-706-5915.

\begin{abstract}
Abnormal $\mathrm{T}$ cell responses are central to the development of autoimmunity and organ damage in systemic lupus erythematosus. Following stimulation, naïve $\mathrm{T}$ cells undergo rapid proliferation, differentiation and cytokine production. Since the initial report, approximately two decades ago, that engagement of CD28 enhances glycolysis but PD-1 and CTLA-4 decrease it, significant information has been generated which has linked metabolic reprogramming with the fate of differentiating $\mathrm{T}$ cell in health and autoimmunity. Herein we summarize how defects in mitochondrial dysfunction, oxidative stress, glycolysis, glutaminolysis and lipid metabolism contribute to proinflammatory $\mathrm{T}$ cell responses in systemic lupus erythematosus and discuss how metabolic defects can be exploited therapeutically.
\end{abstract}

KEYWORDS: T cell metabolism; glycolysis; glutaminolysis; fatty acid oxidation; SLE

\section{ABBREVIATIONS}

Acetyl CoA, acetyl coenzyme A; AOA, (aminooxy)acetic acid; ATP, adenosine triphosphate; ASCT2, alanine, serine, cysteine-preferring transporter 2; BTLA, B and T lymphocyte attenuator; BPTES, bis-2-(5phenylacetamido-1,3,4-thiadiazol-2-yl)ethyl sulfide; CaMK4, calcium/calmodulin-dependent protein kinase IV; CRE, cAMP-response element; CTLA, cytotoxic T lymphocyte-associated protein 4; CREM, cAMP response element modulator; DON, 6-diazo-5-oxo-L-norleucine; EAE, experimental autoimmune encephalomyelitis FAO, fatty acid oxidation; GOT, glutamate oxaloacetate transaminase; HIF, hypoxia-inducible factor; HMG-CoA, hydroxymethylglutaryl-coenzyme A; ICER, inducible cAMP early repressor; IL, interleukin; mTOR, mammalian target of rapamycin; mTORC, mammalian target of rapamycin complex; OXPHOS, oxidative phosphorylation; PDH, pyruvate dehydrogenase; PDP, pyruvate of Creative Commons Attribution 4.0 International License. 
dehydrogenase phosphatase catalytic subunit; PD-1, programmed death 1; PPP, pentose phosphate pathway; PP2A, phosphatase2A; ROR $\gamma t$, retinoic acid-related orphan receptor gamma t; ROS, reactive oxygen species; SLE, systemic lupus erythematosus; STAT3, signal transducer and activator of transcription 3; TCA, tricarboxylic acid; TCR, T-cell receptor; Tfh, follicular helper T cells; Treg, regulatory T cell; 2-DG, 2-deoxy-D glucose

\section{INTRODUCTION}

Systemic lupus erythematosus (SLE) is a chronic autoimmune condition characterized by abnormal $\mathrm{T}$ cell responses to self-antigens resulting in multi-organ involvement including skin, kidney and central nervous system [1]. Following the initial report, two decades ago, that engagement of CD28 leads to enhanced glycolysis in $T$ cells [2] plethora of data contributed to our current understanding on how metabolic processes are involved in the control of various aspects of $\mathrm{T}$ cell signaling, differentiation and pathogenicity allowing for the development of new therapeutic tools or repurposing of already known drugs for the treatment of patients with SLE [3-5]. Advancements in nuclear magnetic resonance spectroscopy and gas chromatography/mass spectrometry have led to the identification of metabolic biomarkers in SLE [3-6]. Herein, we focus on the most recent understandings of the metabolic abnormalities in $\mathrm{T}$ cell subsets in patients with SLE and discuss how metabolic defects can be exploited therapeutically.

\section{MITOCHONDRIAL DYSFUNCTION AND OXIDATIVE STRESS IN SLE}

Increased oxidative stress and altered redox state have been shown to contribute to pathogenesis and tissue damage in patients with SLE by increasing apoptosis, decreasing the clearance of apoptotic material and oxidative modification of numerous biomolecules including DNA and enzymes [7-9]. Reactive oxygen species (ROS) is a group free radical generated during mitochondrial respiration as the result of incomplete reduction of oxygen. Under normal and tightly controlled physiological conditions these molecules play positive role in $\mathrm{CD} 4^{+} \mathrm{T}$ cell signaling and homeostasis such as antigen-specific proliferation, differentiation and cytokine production [10]. Loss of mitochondrial DNA or disruption of mitochondrial complex I or III results in low ROS production and leads to reduced production of interleukin (IL)-2 and IL-4 [11]. In CD4 ${ }^{+} \mathrm{T}$ cells from healthy people engagement of the costimulatory molecule CD28 leads to rapid upregulation of aerobic glycolysis [2], which is in stark contrast to $\mathrm{T}$ cells from patients with SLE which display a chronically activated phenotype, upregulated calcium signaling, enhanced tricarboxylic acid (TCA) cycle activity and dependency on oxidative phosphorylation (OXPHOS) to meet their energetic needs [12]. By shifting away from aerobic glycolysis and pentose phosphate pathway, SLE $\mathrm{CD}^{+} \mathrm{T}$ cells 
eventually exhaust their antioxidant capacity with lower glutathione and NADPH pools $[9,13]$. At the subcellular level, electron microscopy has revealed extensive mitochondrial remodeling in $\mathrm{CD} 4^{+} \mathrm{T}$ cells isolated from people with SLE with the development of hyperpolarized megamitochondria [14], but with paradoxically decreased ATP production and marked leakage of ROS outside of the organelles [15]. Besides chronic stimulation and reliance on OXPHOS, genetic contributors have been postulated to play a role in the abnormal mitochondrial homeostasis. In humans, a SNP variant of the ATP6 or F0F1-ATPase gene (Complex V) has been associated with the development of SLE [16]. Inhibition of this ATPase leads to mitochondrial hyperpolarization and ATP depletion, features similar to those observed in SLE, but in vivo treatment of MRL/lpr mice with Bz-423, an inhibitor of mitochondrial F1F0 ATP synthase, leads to apoptosis of autoreactive $\mathrm{CD}^{+} \mathrm{T}$ cells and suppression of glomerulonephritis [17]. The murine lupus susceptibility locus Sle1c2 defines the Esrrg gene, which is a known regulator of mitochondrial function, and whose decreased expression in lupus-prone mice contributes to mitochondrial dysfunction with increased ROS leakage, abnormal $\mathrm{CD} 4^{+} \mathrm{T}$ cell activation and increased IF $\gamma \gamma$ production $[18,19]$.

Under normal conditions, ROS production by mitochondria is needed to trigger signaling through NF- $\kappa \mathrm{B}, \mathrm{AP} 1$ and NFAT (which bind to the IL-2 promoter) to promote IL-2 production [10,11,20]. High oxidative stress in SLE T cells [21,22], together with the overexpressed serine-threonine protein phosphatase2A (PP2A) leads to T-cell receptor (TCR) rewiring by promoting replacement of $\mathrm{CD} 3 \zeta$ with FceRI $\gamma$ chain coupled with SYK and decreased DNA mehyltransferase 1 activity [21-23]. In parallel, oxidative stress impairs ERK pathway signaling by decreasing protein kinase $C \delta$ (PKC $\delta$ ) phosphorylation and DNA methyltransferase 1 activity, thus directly leading to hypomethylated status of DNA observed in SLE and overexpression of genes associated with pathogenesis of SLE [23-29]. Additionally, ROS triggers activation of mammalian target of rapamycin (mTOR) which is a sensor of mitochondrial hyper polarization and nutrient status [30,31]. In turn, mTOR signaling is directly involved in maintaining and promoting increased mitochondrial biomass by decreasing mitophagy [32]. In contrast to mTORC2, increased activation of mTORC1 is observed in CD4 $4^{+} \mathrm{T}$ cells obtained from SLE patients and lupus prone mice leading to elevated IL-17, IL-4 producing double negative T cell expansion and regulatory $\mathrm{T}$ cell (Treg) depletion [33-35]. Unrestricted mTORC1 signaling leads to severe SLE-related manifestations and this is highlighted in reports of several patients with mutations in tuberous sclerosis complex genes which are known suppressors of mTORC1 signaling [36,37]. Signaling through mTORC1 shifts balance of $\mathrm{CD} 4^{+} \mathrm{T}$ cell 
polarization away from Treg development and toward Th1 and Th17 phenotype by enhancing glycolysis (in these subsets), activates retinoic acid-related orphan receptor gamma t (ROR $\gamma \mathrm{t}$ ) and signal transducer and activator of transcription 3 (STAT3) phosphorylation [33,34,38]. The activity of mTORC1 in Treg is curbed by PP2A and even though mTORC1 does not influence Foxp3 expression and is necessary for the maintenance of suppressive function by Treg cells [39-42]. The inhibition of mTORC1 with rapamycin leads to Treg cell expansion, contraction of IL-17 producing cells and suppression of STAT3 signaling-all of which represent attractive therapeutic targets in people with SLE [43-45]. In addition, in vitro treatment with rapamycin reduces glycolysis and mitochondrial potential and corrects the replacement of $\mathrm{CD} 3 \zeta$ chain on $\mathrm{CD}^{+} \mathrm{T}$ cells $[46,47]$. Moreover, there is complex fine-tuning between mTORC1 and 2 complexes in Treg cells as they transition through various stages of differentiation [39,48].

Table 1. Potential therapeutic target of metabolic pathway in SLE.

\begin{tabular}{|c|c|c|c|}
\hline Therapeutic target & Therapy & Effect on $\mathrm{T}$ cells & Effects on SLE \\
\hline $\begin{array}{l}\text { Hexokinase and } \\
\text { mitochondrial complex I }\end{array}$ & $\begin{array}{l}\text { 2-deoxy-D glucose and } \\
\text { metformin }\end{array}$ & $\begin{array}{l}\text { Decrease IFN } \gamma \text { production } \\
\text { and decreases Tfh cells }\end{array}$ & $\begin{array}{l}\text { Reduces disease activity, and } \\
\text { improve kidney disease }\end{array}$ \\
\hline Glutaminase 1 & $\begin{array}{l}\text { BPTES, CB-839, and } \\
968\end{array}$ & $\begin{array}{l}\text { Reduces Th17 cell } \\
\text { differentiation }\end{array}$ & $\begin{array}{l}\text { Reduces disease activity, and } \\
\text { improve kidney disease }\end{array}$ \\
\hline $\begin{array}{l}\text { Mitochondrial } \\
\text { metabolism }\end{array}$ & $\mathrm{Bz}-423$ & $\begin{array}{l}\text { Promotes autoreactive T cell } \\
\text { apoptosis }\end{array}$ & Reduces disease activity \\
\hline $\begin{array}{l}\text { Glucosylceramide } \\
\text { synthetase }\end{array}$ & NB-DNJ & $\begin{array}{l}\text { Normalizes TCR signaling } \\
\text { and restores BTLA } \\
\text { expression }\end{array}$ & Reduces disease activity \\
\hline Cysteine metabolism & $N$-acetyl cysteine & Inhibits mTOR activity & $\begin{array}{l}\text { Reduces disease activity, and } \\
\text { improve kidney disease }\end{array}$ \\
\hline mTOR signaling & Sirolimus & $\begin{array}{l}\text { Inhibits Th17 differentiation } \\
\text { and promotes Treg } \\
\text { differentiation }\end{array}$ & Reduces disease activity \\
\hline PPAR $\gamma$ & Pioglitazone (agonist) & Promotes Treg expansion & Improves nephritis \\
\hline
\end{tabular}

BTLA, B and T lymphocyte attenuator; BPTES, bis-2-(5-phenylacetamido-1,3,4-thiadiazol-2-yl)ethyl sulfide; mTOR, mammalian target of rapamycin; PPAR $\gamma$, peroxisome proliferator-activated receptor $\gamma$; Tfh, follicular helper T cells.

Germinal center formation depends on the presence of follicular helper $\mathrm{T}$ cells (Tfh) which are expanded in people with SLE [49]. There are conflicting results whether Tfh differentiation is independent or not of mTORC1 activity but more indirect evidence has implicated mTORC2 in Tfh cell differentiation [41,42,50]. Treatment with the reducing agent $N$ acetylcysteine proved beneficial in SLE patients and it reversed the expansion of double negative $\mathrm{T}$ cells, stimulated Foxp3 expression and decreased dsDNA levels [51] (Table 1). Treatment of triple congenic 
B6.Sle1.Sle2.Sle3 lupus-prone mice with metformin, the inhibitor of mitochondrial metabolism, corrected abnormal $\mathrm{T}$ cell metabolism, reduced IFN $\gamma$ production and restored the IL-2 production [47]. Similarly, metformin normalized in vitro IFN $\gamma$ production in $\mathrm{CD}^{+} \mathrm{T}$ cells isolated from patients with SLE [52]. Also, combination of metformin and glycolytic inhibitor 2-deoxy-D glucose (2-DG) showed a synergic effect in vivo and decreased serological markers of SLE disease activity and improved nephritis (Table 1).

\section{GLYCOLYSIS}

Generation of adenosine triphosphate (ATP) in T cells is essential for their survival, activation, differentiation and effector functions. There is marked diversity between $\mathrm{T}$ cells subsets in regard to which metabolic pathway dominates the production of energy [53]. Whether an activated naïve cell will differentiate into effector, regulatory or memory $\mathrm{T}$ cell depends, in part, not just on the cytokine milieu but also on metabolic reprogramming [54-56]. At rest, both naïve $\mathrm{CD}^{+}$and $\mathrm{CD}^{+} \mathrm{T}$ cells fulfill their low metabolic demands by utilizing low rates of OXPHOS [57,58]. Somewhat similar metabolic needs are found in Treg cells and memory $\mathrm{CD}^{+} \mathrm{T}$ cells that predominantly rely on fatty acid oxidation (FAO) and OXPHOS [59-61] for the production of energy. In contrast to this, differentiated effector $\mathrm{CD} 4^{+}$cells prefer glutaminolysis, rapid glycolysis and fatty acid synthesis [59,62] (Figure 1).

Upon activation, naïve $\mathrm{T}$ cells rapidly shift metabolism towards aerobic glycolysis with large glucose consumption $[58,63]$. From the efficiency standpoint oxidative glycolysis is less efficient than TCA cycle coupled to OXPHOS, but serves as a means to engage pentose phosphate pathway (PPP) to generate nucleotides, amino acids, lipids and NADPH to support an increase in the levels of antioxidants in the cell [64,65]. Pyruvate is the end product of glycolysis, and at rest, it is more likely to be converted to lactate rather than to enter the TCA cycle as acetyl coenzyme A (acetyl-CoA) [66]. End products of TCA cycle are $\mathrm{NADH}, \mathrm{FADH}_{2}$ and amino acids. $\mathrm{NADH}$ enters OXPHOS on the inner mitochondrial membrane to generate maximum ATPs. This process is prerequisite for Th1 and Th17 differentiation [67]. Once $\mathrm{CD} 4^{+} \mathrm{T}$ cells are activated, the engagement of TCR and co-stimulatory receptors leads to the rapid upregulation of the glucose transporter Glut1 via PI3K-Akt signaling (that can activate mTOR) and upregulation of key downstream enzymes via hypoxia-inducible factor (HIF)-1a and Myc [2,64] (Figure 1). The opposite occurs with the engagement of cytotoxic T lymphocyte-associated protein 4 (CTLA-4) and programmed death 1 (PD-1) [2,68]. 


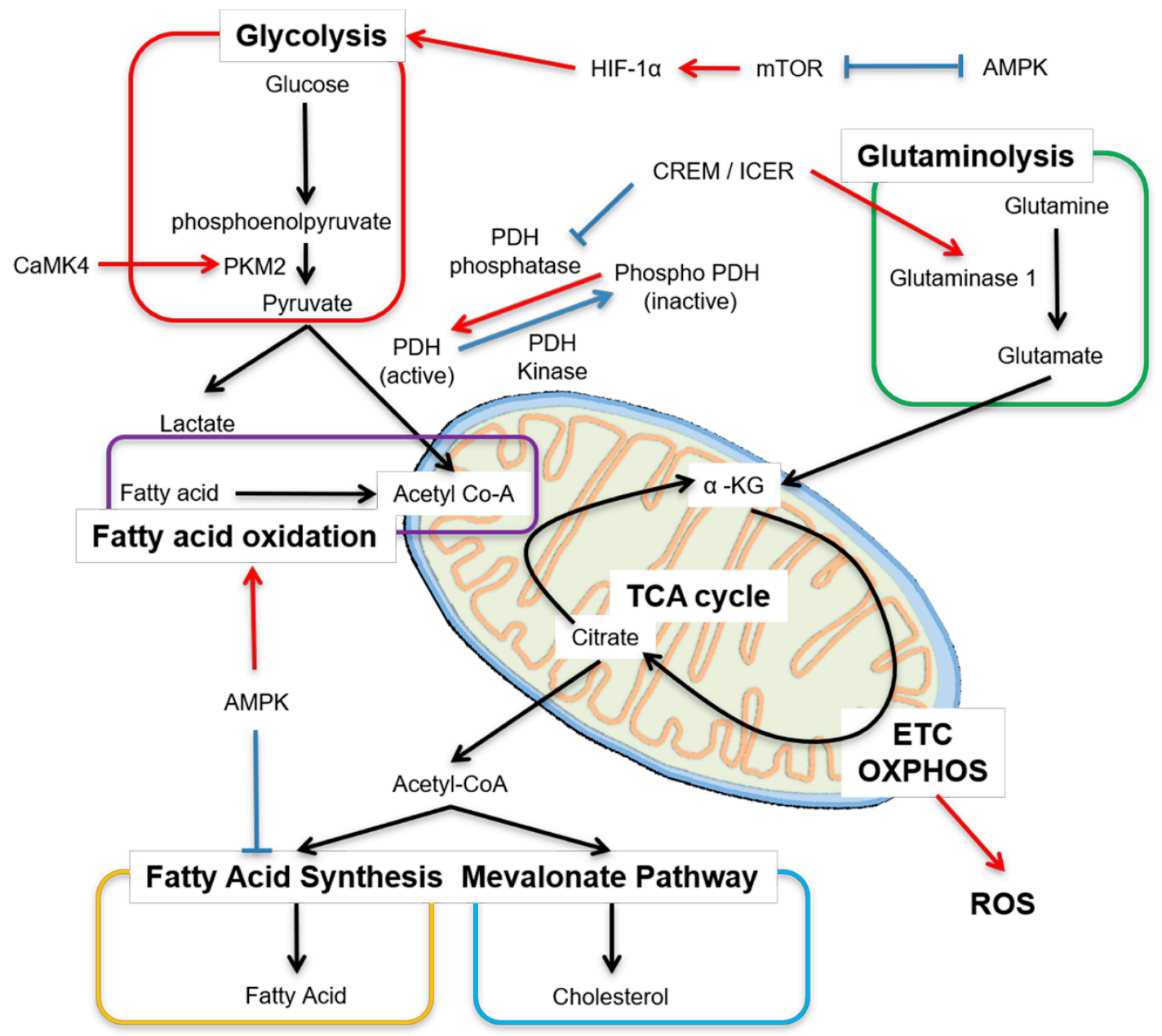

Figure 1. Main metabolic pathways in T cells. Cellular metabolism is controlled by many factors, including transcription factors. Red arrow means "enhance or activate", whereas blue line means "inhibit or inactivate”. Acetyl Co-A, acetyl coenzyme A; mTOR, mammalian target of rapamycin; AMPK, adenosine monophosphate activated protein kinase; HIF-1a, hypoxia inducible factor 1 alpha; PKM2, pyruvate kinase muscle isozyme 2; CaMK4, calcium/calmodulin-dependent protein kinase IV; PDH, pyruvate dehydrogenase; ICER, inducible cAMP early repressor; $\alpha-K G$, $a$-ketoglutarate; ETC, electron transport chain; OXPHOS, oxidative phosphorylation; ROS, reactive oxygen species.

Several metabolic abnormalities have been observed in SLE T cells. Chronic antigenic stimulation leads to increased OXPHOS as measured by the oxygen consumption which can be replicated in healthy cells following repetitive antigen stimulation or in T cells lacking HIF-1a [12,69,70]. As discussed above, in SLE T cells OXPHOS fails to generate sufficient ATP compared to healthy $\mathrm{T}$ cells despite having enlarged mitochondrial biomass. Therefore, enhanced secondary glycolysis is observed in SLE [71]. Overexpression of Glut1 in murine $\mathrm{T}$ cells results in the development of lupus-like disease in older mice and selective accumulation of effector and follicular T cells [72]. More recently, Glut1 overexpression was found in effector memory $\mathrm{CD} 4^{+} \mathrm{T}$ cells in people with active and inactive SLE [73]. Increased Glut1 expression can be reversed by inhibiting the $\mathrm{T}$ cell 
restricted serine/threonine kinase, calcium/calmodulin-dependent protein kinase IV (CaMK4) which is overexpressed in SLE T cells [73,74]. Pharmacological inhibition or genetic deletion of CaMK4 decreases glycolysis and ameliorates disease activity in MRL/lpr mice [75-77]. CaMK4 activates AKT/mTOR pathway but is also found to promote glycolysis by binding and augmenting the activity of pyruvate kinase M2, the final ratelimiting enzyme in glycolysis, underlying autoimmunity associated with Th17 in SLE [78,79]. A distinct feature of Th17 cells, which are exaggerated in patients with SLE, is the overexpression of HIF-1 $\alpha$ and reduced pyruvate dehydrogenase (PDH) activity that triggers metabolic shift leading to enhanced pyruvate to lactate production and decreased pyruvate to acetyl-CoA [62,80] (Figure 1). The enzymatic activity of PDH is inhibited in Th17 cells to promote conversion of pyruvate to lactate by promoting the activity of PDH kinase, which phosphorylates PDH (active form) to phospho-PDH (inactive form) [62]. On the other hand, PDH phosphatase makes PDH active (Figure 1) [80]. The cAMP response element modulator (CREM) moderates the transcription of cAMP-responsible genes [81]. CREM splice variants CREMa and inducible cAMP early repressor (ICER) are increased in Th17 cells and more so in people with SLE [82]. ICER binds the cAMP-response element (CRE) of PDH phosphatase catalytic subunit 2 (Pdp2) promoter, suppresses the Pdp2 gene expression and reduces PDH enzyme activity [80]. Forced expression of PDP2 into naïve $\mathrm{CD}^{+}$cells reduce Th17 cell differentiation [80]. These data demonstrate that molecules which were previously connected to $\mathrm{T}$ cell effector function accomplish their effects by directly controlling the expression of distinct enzymes involved in cell metabolism.

Because Tfh cells are also involved in the pathogenesis of SLE and their numbers are expanded, in vivo treatment of several lupus-prone mice with 2-DG normalized Tfh cells numbers and reversed serological markers of lupus but more importantly it did not affect humoral responses that preferentially relied on glutaminolysis [82,83]. This observation is of paramount importance because it points to the need to understand the differential regulation of metabolic pathways between the development of a normal and an autoimmune/inflammatory process.

Compared to $\mathrm{CD} 4^{+} \mathrm{T}$ cells, stimulated cytotoxic $\mathrm{CD} 8^{+}$cells undergo more rapid growth and proliferation and retain preferential glycolytic metabolism resistant to metabolic inhibition [58]. CD38 is ecto-enzyme NADase, a co-factor of OXPHOS, found to be overexpressed on SLE T cell subsets $[84,85]$. In vitro generated $\mathrm{T}$ cells lacking CD38 have enhanced oxidative phosphorylation and higher glutaminolysis rates [86]. Recently we found that $\mathrm{CD} 8^{+} \mathrm{CD} 38^{\text {high }}$ population is expanded in subset of patients with SLE who have increased rates of infections and these cells had 
decreased cytotoxic capacity, degranulation and expression of cytolytic enzymes [87]. These findings point to the need to develop biologics or drugs to inhibit $\mathrm{CD} 38$ in order to restore $\mathrm{CD} 8^{+}$cytotoxic $\mathrm{T}$ cell responses and avert infections, which are still the main cause of mortality in people with SLE.

\section{GLUTAMINE METABOLISM}

Glutamine is a non-essential amino acid and another important metabolic fuel besides glucose. Glutaminolysis has a vital role in energy production in proliferating cells, including $T$ cells. Glutamine enters the cell through the alanine, serine, cysteine-preferring transporter 2 (ASCT2) and is converted to glutamate, which is further transformed into aketoglutarate, an intermediate of the TCA cycle. Glutaminolysis is requisite for mTORC activation [88] and for the generation of glutathione, which neutralized ROS and is essential for Th17 cell differentiation [89,90]. Glutamine metabolism is involved $\mathrm{T}$ cell differentiation and fate. Th17 cells depend on glutaminolysis more than Th1, Th2 and Treg cells [88]. Depletion of glutamine or deficiency of the transporter ASCT2 reduces Th1 and Th17 differentiation [91]. Glutaminase which generates glutamate from glutamine has two isoforms: kidney-type glutaminase 1 and livertype glutaminase 2. Glutaminase 1 has more enzymatic activity than glutaminase 2 and $\mathrm{T}$ cells express mainly glutaminase 1 [88]. The transcription factor ICER binds the promoter lesion of glutaminase 1 and enhances its expression and promotes glutaminolysis [88] (Figure 1). Inhibition of glutaminase 1 or deficiency of glutaminase 1 reduces Th17 cell differentiation [88,92] and disease activity in animals subjected to experimental autoimmune encephalomyelitis (EAE). The glutaminase inhibitor, Bis-2-(5-phenylacetamido-1,3,4-thiadiazol-2-yl)ethyl sulfide (BPTES)], also ameliorates the disease activity in MRL/pr mice [93] (Table 1).

Glutamate can generate $\alpha$-ketoglutarate through direct deamination by glutamate dehydrogenase or through transamination to produce the nonessential amino acid alanine or aspartate. Glutamate oxaloacetate transaminase 1 (GOT1) catalyzes the conversion of glutamate to aketoglutarate via the transamination of oxaloacetate to aspartate. Selective inhibition of GOT1 with (aminooxy)acetic acid (AOA) reduces Th17 differentiation and enhances Treg cells differentiation and ameliorates EAE [94].

Tfh cells are increased in both the patients with SLE and lupus-prone mice and their numbers correlate with disease activity. Glutaminolysis also regulates $\mathrm{Tfh}$ and inhibition of glutaminolysis with the glutamine analog 6-Diazo-5-oxo-L-norleucine (DON) reduces the frequency of Tfh cells and the production of dsDNA antibody [83]. 


\section{LIPID METABOLISM}

Fatty acid oxidation (FAO) is a mitochondrial aerobic process responsible for producing acetyl CoA from fatty acids which enters the TCA cycle (Figure 1). Quiescent T cells and Treg cells use mainly FAO. The addition of fatty acids to cells in culture increases Treg cell, but not effector $\mathrm{T}$ cell differentiation [95]. Adenosine monophosphate activated protein kinase (AMPK) is serine/threonine kinase and one of the key metabolic regulators besides mTORC. AMPK inhibits MTORC activity and vice versa. AMPK increases the expression of carnitine palmitoyl transferase I (CPT I), a rate-limiting enzyme in FAO and promotes FAO, whereas AMPKdependent phosphorylation of acetyl-CoA carboxylase 1 (ACC1) inhibits fatty acid synthesis [96,97]. In fact, Treg cells have high expression levels of CPT I, which supports Treg cells to use multiple fuel sources, including FAO [59,98].

Biosynthesis of fatty acids and cholesterol is essential for $\mathrm{T}$ cell proliferation, and differentiation in effector T cells, especially Th17 cells. Fatty acid synthesis is a cytosolic process whereby acetyl CoA is converted to fatty acids. ACC1, the rate-limiting enzyme for fatty acid synthesis promotes metabolic reprograming due to TCR stimulation, and enhances Th1 and Th17 cell differentiation [61,99,100]. Cholesterol is synthesized from acetyl CoA by the hydroxymethylglutaryl-coenzyme A (HMG-CoA). Statin, the inhibitors of HMG-CoA reductase, reduce Th17 cell differentiation [101].

Lipid rafts are subdomains of the plasma membrane that are composed of cholesterol and glycosphingolipids. $\mathrm{CD}^{+} \mathrm{T}$ cells from people with SLE have an altered profile of lipid raft-associated glycosphingolipids compared with that of healthy controls [102]. $N$-butyldeoxynojirimycin (NB-DNJ), a glucosylceramide synthase inhibitor, normalizes lipid metabolism in $\mathrm{CD}^{+} \mathrm{T}$ cells from the patients with SLE [102]. Furthermore, NB-DNJ treatment restores the functionality of $\mathrm{B}$ and $\mathrm{T}$ lymphocyte attenuator (BTLA), an inhibitory receptor, similar to CTLA-4 and PD-1, in lupus $\mathrm{CD} 4^{+} \mathrm{T}$ cells [103] (Table 1). The synthesis of glycosphingolipids in $\mathrm{T}$, $\mathrm{B}$ cells and kidney is regulated by the transcription factor Friend leukaemia integration 1 (FLI1). A polymorphic microsatellite consisting of GA repeats within the proximal promoter of Fli1 gene is shorter in three different lupus-prone mice, and the length of the microsatellite correlates inversely with the activity of the promoter [104]. Overexpression of FLI1 in mice results in a progressive immunological renal disease and renal failure caused by tubulointerstitial nephritis and immune-complex glomerulonephritis [105]. Fli1 ${ }^{+-}$T cells from MRL/lpr mice transferred to Rag1-deficient mice have reduced levels of glycosphingolipids and diminished TCR activation compared with transferred Fli1 ${ }^{++}$T cells [106]. 
The formation of lipid rafts on the surface of $\mathrm{T}$ cells is important during $\mathrm{T}$ cell activation and T cells from people with SLE aggregate lipid rafts on the surface membrane spontaneously [105] and enable faster and stronger CD3-mediated cell signaling. Enhanced lipid raft aggregation in the absence of obvious antigenic stimulation implies that the surface membrane is more fluid and molecules move around faster. There is need to gain more information on metabolic factors that regulate the expression of lipids on the surface membrane of $\mathrm{T}$ cells so we may control their signaling capacity.

\section{CONCLUSIONS AND FUTURE DIRECTIONS}

We have discussed in detail most recent information on the metabolic aberrations which account for the abnormal function of $\mathrm{T}$ cell subsets in people with SLE. We have learned that specific effector T cell function is defined by metabolic processes which dictate the sources of energy generation. More importantly, we have learned that molecules such as kinases (CaMK4) or transcription factors (CREM/ICER) which had previously been linked to abnormal effector $\mathrm{T}$ cell function in SLE accomplish their effects by directly controlling the function of metabolic enzymes involved in glycolysis and glutaminolysis. It is certain that in the near future we will discover that other known determinants of effector $\mathrm{T}$ cell function accomplish their effect through the control of metabolic enzymes. Therefore, it is proper to assume that what each $\mathrm{T}$ cell does depends on its source and disposal of energy. Besides though energy, each metabolic pathway generates metabolites which are important to construct molecules needed in other cells processes including building blocks for cell growth and differentiation. It is important to consider that metabolic processes may behave differently during the development of a normal immune response and in the context of autoimmune or inflammatory context. Such understanding should influence the design of approaches to boost a normal response and suppress an inflammatory one. We expect that modulators of metabolic processes will be important in controlling abnormal $\mathrm{T}$ cell behavior and although most probably they alone will not be sufficient to control autoimmune pathology, they may be perfect adjuvants to standard treatment with immunosuppressive drugs and help limit their side effects by decreasing their dose. Finally, we should state unequivocally, that more research is needed to completely understand the complex metabolic processes that are responsible for the well-known aberrant function of $\mathrm{T}$ cell subsets including Treg, CD ${ }^{+}$ cytotoxic, $\mathrm{T}$ effector and $\mathrm{T}$ follicular helper cells. Very little, if anything, is known on the metabolism of lipids in SLE immune cells. For example, does cholesterol control immune cell function, and does cholesterol of fatty 
acids control immune cell membrane physical chemistry behavior. For example, what accounts for the spontaneous formation of lipid rafts on the surface membrane of $\mathrm{T}$ cells. It is plausible that aberrant lipid/sphingolipid metabolism contributes to their formation and indirectly to the enhanced early signaling events [22].

\section{CONFLICTS OF INTEREST}

The authors declare that they have no conflicts of interest.

\section{FUNDING}

This work was supported by NIH grants R01AR064350; R37 AI 49954 (to GCT) and by a SENSHIN Medical Research Foundation grant (to MK).

\section{REFERENCES}

1. Tsokos GC, Lo MS, Costa Reis P, Sullivan KE. New insights into the immunopathogenesis of systemic lupus erythematosus. Nat Rev Rheumatol. 2016;12(12):716-30. doi: 10.1038/nrrheum.2016.186

2. Frauwirth KA, Riley JL, Harris MH, Parry RV, Rathmell JC, Plas DR, et al. The CD28 signaling pathway regulates glucose metabolism. Immunity. 2002;16(6):769-77. doi: 10.1016/s1074-7613(02)00323-0

3. Bengtsson AA, Trygg J, Wuttge DM, Sturfelt G, Theander E, Donten M, et al. Metabolic Profiling of Systemic Lupus Erythematosus and Comparison with Primary Sjogren's Syndrome and Systemic Sclerosis. PLoS One. 2016;11(7):e0159384. doi: 10.1371/journal.pone.0159384

4. Wu T, Xie C, Han J, Ye Y, Weiel J, Li Q, et al. Metabolic disturbances associated with systemic lupus erythematosus. PLoS One. 2012;7(6):e37210. doi: 10.1371/journal.pone.0037210

5. Saegusa J, Irino Y, Yoshida M, Tanaka S, Kogata Y, Kageyama G, et al. GC/MSbased metabolomics detects metabolic alterations in serum from SLE patients. Clin Exp Rheumatol. 2014;32(1):148.

6. Ouyang X, Dai Y, Wen JL, Wang LX. (1)H NMR-based metabolomic study of metabolic profiling for systemic lupus erythematosus. Lupus. 2011;20(13):1411-20. doi: 10.1177/0961203311418707

7. Lightfoot YL, Blanco LP, Kaplan MJ. Metabolic abnormalities and oxidative stress in lupus. Curr Opin Rheumatol. 2017;29(5):442-9. doi: 10.1097/BOR.0000000000000413

8. Wang G, Pierangeli SS, Papalardo E, Ansari GA, Khan MF. Markers of oxidative and nitrosative stress in systemic lupus erythematosus: correlation with disease activity. Arthritis Rheum. 2010;62(7):2064-72. doi: 10.1002/art.27442

9. Perl A. Oxidative stress in the pathology and treatment of systemic lupus erythematosus. Nat Rev Rheumatol. 2013;9(11):674-86. doi: 10.1038/nrrheum.2013.147

10. Sena LA, Li S, Jairaman A, Prakriya M, Ezponda T, Hildeman DA, et al. Mitochondria are required for antigen-specific $\mathrm{T}$ cell activation through 
reactive oxygen species signaling. Immunity. 2013;38(2):225-36. doi: 10.1016/j.immuni.2012.10.020

11. Kaminski MM, Sauer SW, Klemke CD, Suss D, Okun JG, Krammer PH, et al. Mitochondrial reactive oxygen species control $\mathrm{T}$ cell activation by regulating IL-2 and IL-4 expression: mechanism of ciprofloxacin-mediated immunosuppression. J Immunol. 2010;184(9):4827-41. doi: 10.4049/jimmunol.0901662

12. Wahl DR, Petersen B, Warner R, Richardson BC, Glick GD, Opipari AW. Characterization of the metabolic phenotype of chronically activated lymphocytes. Lupus. 2010;19(13):1492-501. doi: 10.1177/0961203310373109

13. Gergely P Jr, Grossman C, Niland B, Puskas F, Neupane H, Allam F, et al. Mitochondrial hyperpolarization and ATP depletion in patients with systemic lupus erythematosus. Arthritis Rheum. 2002;46(1):175-90. doi: 10.1002/15290131(200201)46:1<175::AID-ART10015>3.0.CO;2-H

14. Doherty E, Oaks Z, Perl A. Increased mitochondrial electron transport chain activity at complex I is regulated by $N$-acetylcysteine in lymphocytes of patients with systemic lupus erythematosus. Antioxid Redox Signal. 2014;21(1):56-65. doi: 10.1089/ars.2013.5702

15. Perl A, Gergely P Jr, Banki K. Mitochondrial dysfunction in T cells of patients with systemic lupus erythematosus. Int Rev Immunol. 2004;23(3-4):293-313. doi: 10.1080/08830180490452576

16. Vyshkina T, Sylvester A, Sadiq S, Bonilla E, Canter JA, Perl A, et al. Association of common mitochondrial DNA variants with multiple sclerosis and systemic lupus erythematosus. Clin Immunol. 2008;129(1):31-5. doi: 10.1016/j.clim.2008.07.011

17. Bednarski JJ, Warner RE, Rao T, Leonetti F, Yung R, Richardson BC, et al. Attenuation of autoimmune disease in Fas-deficient mice by treatment with a cytotoxic benzodiazepine. Arthritis Rheum. 2003;48(3):757-66. doi: 10.1002/art.10968

18. Perry DJ, Yin Y, Telarico T, Baker HV, Dozmorov I, Perl A, et al. Murine lupus susceptibility locus Sle1c2 mediates CD4+ T cell activation and maps to estrogen-related receptor gamma. J Immunol. 2012;189(2):793-803. doi: 10.4049/jimmunol.1200411

19. Huss JM, Garbacz WG, Xie W. Constitutive activities of estrogen-related receptors: Transcriptional regulation of metabolism by the ERR pathways in health and disease. Biochim Biophys Acta. 2015;1852(9):1912-27. doi: 10.1016/j.bbadis.2015.06.016

20. Chow CW, Rincon M, Davis RJ. Requirement for transcription factor NFAT in interleukin-2 expression. Mol Cell Biol. 1999;19(3):2300-7. doi: 10.1128/mcb.19.3.2300

21. Tsokos GC. Systemic lupus erythematosus. N Engl J Med. 2011;365(22):2110-21. doi: 10.1056/NEJMra1100359

22. Krishnan S, Farber DL, Tsokos GC. T cell rewiring in differentiation and disease. J Immunol. 2003;171(7):3325-31. doi: 10.4049/jimmunol.171.7.3325

23. Sunahori K, Nagpal K, Hedrich CM, Mizui M, Fitzgerald LM, Tsokos GC. The catalytic subunit of protein phosphatase 2A (PP2Ac) promotes DNA 
hypomethylation by suppressing the phosphorylated mitogen-activated protein kinase/extracellular signal-regulated kinase (ERK) kinase (MEK)/phosphorylated ERK/DNMT1 protein pathway in T-cells from controls and systemic lupus erythematosus patients. J Biol Chem. 2013;288(30):2193644. doi: 10.1074/jbc.M113.467266

24. Gorelik G, Fang JY, Wu A, Sawalha AH, Richardson B. Impaired T cell protein kinase $C$ delta activation decreases ERK pathway signaling in idiopathic and hydralazine-induced lupus. J Immunol. 2007;179(8):5553-63. doi: 10.4049/jimmunol.179.8.5553

25. Gorelik GJ, Yarlagadda S, Patel DR, Richardson BC. Protein kinase Cdelta oxidation contributes to ERK inactivation in lupus T cells. Arthritis Rheum. 2012;64(9):2964-74. doi: 10.1002/art.34503

26. Kilgore JA, Du X, Melito L, Wei S, Wang C, Chin HG, et al. Identification of DNMT1 selective antagonists using a novel scintillation proximity assay. J Biol Chem. 2013;288(27):19673-84. doi: 10.1074/jbc.M112.443895

27. Liu Y, Chen Y, Richardson B. Decreased DNA methyltransferase levels contribute to abnormal gene expression in "senescent” CD4(+)CD28(-) T cells. Clin Immunol. 2009;132(2):257-65. doi: 10.1016/j.clim.2009.03.529

28. Strickland FM, Li Y, Johnson K, Sun Z, Richardson BC. CD4(+) T cells epigenetically modified by oxidative stress cause lupus-like autoimmunity in mice. J Autoimmun. 2015;62:75-80. doi: 10.1016/j.jaut.2015.06.004

29. Ray D, Strickland FM, Richardson BC. Oxidative stress and dietary micronutrient deficiencies contribute to overexpression of epigenetically regulated genes by lupus T cells. Clin Immunol. 2018;196:97-102. doi: 10.1016/j.clim.2018.04.003

30. Kim SG, Buel GR, Blenis J. Nutrient regulation of the mTOR complex 1 signaling pathway. Mol Cells. 2013;35(6):463-73. doi: 10.1007/s10059-013-0138-2

31. Fernandez D, Perl A. mTOR signaling: a central pathway to pathogenesis in systemic lupus erythematosus? Discov Med. 2010;9(46):173-8.

32. Bartolome A, Garcia-Aguilar A, Asahara SI, Kido Y, Guillen C, Pajvani UB, et al. MTORC1 Regulates both General Autophagy and Mitophagy Induction after Oxidative Phosphorylation Uncoupling. Mol Cell Biol. 2017;37(23). doi: 10.1128/MCB.00441-17

33. Delgoffe GM, Kole TP, Zheng Y, Zarek PE, Matthews KL, Xiao B, et al. The mTOR kinase differentially regulates effector and regulatory $\mathrm{T}$ cell lineage commitment. Immunity. 2009;30(6):832-44. doi: 10.1016/j.immuni.2009.04.014

34. Nagai S, Kurebayashi Y, Koyasu S. Role of PI3K/Akt and mTOR complexes in Th17 cell differentiation. Ann N Y Acad Sci. 2013;1280:30-4. doi: 10.1111/nyas.12059

35. Delgoffe GM, Pollizzi KN, Waickman AT, Heikamp E, Meyers DJ, Horton MR, et al. The kinase mTOR regulates the differentiation of helper $\mathrm{T}$ cells through the selective activation of signaling by mTORC1 and mTORC2. Nat Immunol. 2011;12(4):295-303. doi: 10.1038/ni.2005

36. Singh N, Birkenbach M, Caza T, Perl A, Cohen PL. Tuberous sclerosis and fulminant lupus in a young woman. J Clin Rheumatol. 2013;19(3):134-7. doi: 10.1097/RHU.0b013e318289c033 
37. Henske EP, Jozwiak S, Kingswood JC, Sampson JR, Thiele EA. Tuberous sclerosis complex. Nat Rev Dis Primers. 2016;2:16035. doi: 10.1038/nrdp.2016.35

38. Shi LZ, Wang R, Huang G, Vogel P, Neale G, Green DR, et al. HIF1alphadependent glycolytic pathway orchestrates a metabolic checkpoint for the differentiation of TH17 and Treg cells. J Exp Med. 2011;208(7):1367-76. doi: 10.1084/jem.20110278

39. Zeng H, Yang K, Cloer C, Neale G, Vogel P, Chi H. mTORC1 couples immune signals and metabolic programming to establish T(reg)-cell function. Nature. 2013;499(7459):485-90. doi: 10.1038/nature12297

40. Apostolidis SA, Rodriguez-Rodriguez N, Suarez-Fueyo A, Dioufa N, Ozcan E, Crispin JC, et al. Phosphatase PP2A is requisite for the function of regulatory T cells. Nat Immunol. 2016;17(5):556-64. doi: 10.1038/ni.3390

41. Ray JP, Staron MM, Shyer JA, Ho PC, Marshall HD, Gray SM, et al. The Interleukin-2-mTORc1 Kinase Axis Defines the Signaling, Differentiation, and Metabolism of $\mathrm{T}$ Helper 1 and Follicular B Helper T Cells. Immunity. 2015;43(4):690-702. doi: 10.1016/j.immuni.2015.08.017

42. Ramiscal RR, Parish IA, Lee-Young RS, Babon JJ, Blagih J, Pratama A, et al. Attenuation of AMPK signaling by ROQUIN promotes $\mathrm{T}$ follicular helper cell formation. Elife. 2015;4. doi: 10.7554/eLife.08698

43. Lui SL, Tsang R, Chan KW, Zhang F, Tam S, Yung S, et al. Rapamycin attenuates the severity of established nephritis in lupus-prone NZB/W F1 mice. Nephrol Dial Transplant. 2008;23(9):2768-76. doi: 10.1093/ndt/gfn216

44. Lai ZW, Borsuk R, Shadakshari A, Yu J, Dawood M, Garcia R, et al. Mechanistic target of rapamycin activation triggers IL-4 production and necrotic death of double-negative $\mathrm{T}$ cells in patients with systemic lupus erythematosus. J Immunol. 2013;191(5):2236-46. doi: 10.4049/jimmunol.1301005

45. Kato H, Perl A. Mechanistic target of rapamycin complex 1 expands Th17 and IL-4+ CD4-CD8- double-negative $\mathrm{T}$ cells and contracts regulatory $\mathrm{T}$ cells in systemic lupus erythematosus. J Immunol. 2014;192(9):4134-44. doi: 10.4049/jimmunol.1301859

46. Fernandez DR, Telarico T, Bonilla E, Li Q, Banerjee S, Middleton FA, et al. Activation of mammalian target of rapamycin controls the loss of TCRzeta in lupus $\mathrm{T}$ cells through HRES-1/Rab4-regulated lysosomal degradation. J Immunol. 2009;182(4):2063-73. doi: 10.4049/jimmunol.0803600

47. Yin Y, Choi SC, Xu Z, Perry DJ, Seay H, Croker BP, et al. Normalization of CD4 T cell metabolism reverses lupus. Sci Transl Med. 2015;7(274):274ra18. doi: 10.1126/scitranslmed.aaa0835

48. Shrestha S, Yang K, Guy C, Vogel P, Neale G, Chi H. Treg cells require the phosphatase PTEN to restrain TH1 and TFH cell responses. Nat Immunol. 2015;16(2):178-87. doi: 10.1038/ni.3076

49. Simpson N, Gatenby PA, Wilson A, Malik S, Fulcher DA, Tangye SG, et al. Expansion of circulating $\mathrm{T}$ cells resembling follicular helper $\mathrm{T}$ cells is a fixed phenotype that identifies a subset of severe systemic lupus erythematosus. Arthritis Rheum. 2010;62(1):234-44. doi: 10.1002/art.25032 
50. Zeng H, Cohen S, Guy C, Shrestha S, Neale G, Brown SA, et al. mTORC1 and mTORC2 Kinase Signaling and Glucose Metabolism Drive Follicular Helper T Cell Differentiation. Immunity. 2016;45(3):540-54. doi: 10.1016/j.immuni.2016.08.017

51. Lai ZW, Hanczko R, Bonilla E, Caza TN, Clair B, Bartos A, et al. N-acetylcysteine reduces disease activity by blocking mammalian target of rapamycin in $\mathrm{T}$ cells from systemic lupus erythematosus patients: a randomized, doubleblind, placebo-controlled trial. Arthritis Rheum. 2012;64(9):2937-46. doi: 10.1002/art.34502

52. Titov AA, Baker HV, Brusko TM, Sobel ES, Morel L. Metformin Inhibits the Type 1 IFN Response in Human CD4(+) T Cells. J Immunol. 2019;203(2):338-48. doi: 10.4049/jimmunol.1801651

53. Yang Z, Matteson EL, Goronzy JJ, Weyand CM. T-cell metabolism in autoimmune disease. Arthritis Res Ther. 2015;17:29. doi: 10.1186/s13075-0150542-4

54. Buck MD, O'Sullivan D, Pearce EL. T cell metabolism drives immunity. J Exp Med. 2015;212(9):1345-60. doi: 10.1084/jem.20151159

55. Loftus RM, Finlay DK. Immunometabolism: Cellular Metabolism Turns Immune Regulator. J Biol Chem. 2016;291(1):1-10. doi: 10.1074/jbc.R115.693903

56. Palmer CS, Ostrowski M, Balderson B, Christian N, Crowe SM. Glucose metabolism regulates $\mathrm{T}$ cell activation, differentiation, and functions. Front Immunol. 2015;6:1. doi: 10.3389/fimmu.2015.00001

57. Fox CJ, Hammerman PS, Thompson CB. Fuel feeds function: energy metabolism and the T-cell response. Nat Rev Immunol. 2005;5(11):844-52. doi: 10.1038/nri1710

58. Cao Y, Rathmell JC, Macintyre AN. Metabolic reprogramming towards aerobic glycolysis correlates with greater proliferative ability and resistance to metabolic inhibition in CD8 versus CD4 T cells. PLoS One. 2014;9(8):e104104. doi: 10.1371/journal.pone.0104104

59. Michalek RD, Gerriets VA, Jacobs SR, Macintyre AN, MacIver NJ, Mason EF, et al. Cutting edge: distinct glycolytic and lipid oxidative metabolic programs are essential for effector and regulatory CD4+ $\mathrm{T}$ cell subsets. J Immunol. 2011;186(6):3299-303. doi: 10.4049/jimmunol.1003613

60. Beier UH, Angelin A, Akimova T, Wang L, Liu Y, Xiao H, et al. Essential role of mitochondrial energy metabolism in Foxp3(+) T-regulatory cell function and allograft survival. FASEB J. 2015;29(6):2315-26. doi: 10.1096/fj.14-268409

61. Berod L, Friedrich C, Nandan A, Freitag J, Hagemann S, Harmrolfs K, et al. De novo fatty acid synthesis controls the fate between regulatory $\mathrm{T}$ and $\mathrm{T}$ helper 17 cells. Nat Med. 2014;20(11):1327-33. doi: 10.1038/nm.3704

62. Gerriets VA, Kishton RJ, Nichols AG, Macintyre AN, Inoue M, Ilkayeva O, et al. Metabolic programming and PDHK1 control CD4+ $\mathrm{T}$ cell subsets and inflammation. J Clin Invest. 2015;125(1):194-207. doi: 10.1172/JCI76012

63. Roos D, Loos JA. Changes in the carbohydrate metabolism of mitogenically stimulated human peripheral lymphocytes. II. Relative importance of glycolysis and oxidative phosphorylation on phytohaemagglutinin 
stimulation. Exp Cell Res. 1973;77(1):127-35. doi: 10.1016/0014-4827(73)905612

64. Wang R, Dillon CP, Shi LZ, Milasta S, Carter R, Finkelstein D, et al. The transcription factor Myc controls metabolic reprogramming upon $\mathrm{T}$ lymphocyte activation. Immunity. 2011;35(6):871-82. doi: 10.1016/j.immuni.2011.09.021

65. Lane AN, Fan TW. Regulation of mammalian nucleotide metabolism and biosynthesis. Nucleic Acids Res. 2015;43(4):2466-85. doi: 10.1093/nar/gkv047

66. Brand K, Aichinger S, Forster S, Kupper S, Neumann B, Nurnberg W, et al. Cellcycle-related metabolic and enzymatic events in proliferating rat thymocytes. Eur J Biochem. 1988;172(3):695-702. doi: 10.1111/j.1432-1033.1988.tb13944.x

67. Bailis W, Shyer JA, Zhao J, Canaveras JCG, Al Khazal FJ, Qu R, et al. Distinct modes of mitochondrial metabolism uncouple $\mathrm{T}$ cell differentiation and function. Nature. 2019;571(7765):403-7. doi: 10.1038/s41586-019-1311-3

68. Parry RV, Chemnitz JM, Frauwirth KA, Lanfranco AR, Braunstein I, Kobayashi SV, et al. CTLA-4 and PD-1 receptors inhibit T-cell activation by distinct mechanisms. Mol Cell Biol. 2005;25(21):9543-53. doi: 10.1128/MCB.25.21.95439553.2005

69. Semenza GL, Jiang BH, Leung SW, Passantino R, Concordet JP, Maire P, et al. Hypoxia response elements in the aldolase $\mathrm{A}$, enolase 1 , and lactate dehydrogenase A gene promoters contain essential binding sites for hypoxiainducible factor $1 . \mathrm{J}$ Biol Chem. 1996;271(51):32529-37. doi: 10.1074/jbc.271.51.32529

70. Lum JJ, Bui T, Gruber M, Gordan JD, DeBerardinis RJ, Covello KL, et al. The transcription factor HIF-1alpha plays a critical role in the growth factordependent regulation of both aerobic and anaerobic glycolysis. Genes Dev. 2007;21(9):1037-49. doi: 10.1101/gad.1529107

71. Yin Y, Choi SC, Xu Z, Zeumer L, Kanda N, Croker BP, et al. Glucose Oxidation Is Critical for CD4+ T Cell Activation in a Mouse Model of Systemic Lupus Erythematosus. J Immunol. 2016;196(1):80-90. doi: 10.4049/jimmunol.1501537

72. Jacobs SR, Herman CE, Maciver NJ, Wofford JA, Wieman HL, Hammen JJ, et al. Glucose uptake is limiting in $\mathrm{T}$ cell activation and requires CD28-mediated Akt-dependent and independent pathways. J Immunol. 2008;180(7):4476-86. doi: 10.4049/jimmunol.180.7.4476

73. Koga T, Sato T, Furukawa K, Morimoto S, Endo Y, Umeda M, et al. Promotion of Calcium/Calmodulin - Dependent Protein Kinase 4 by GLUT1 - Dependent Glycolysis in Systemic Lupus Erythematosus. Arthritis Rheumatol. 2019;71(5):766-772. doi: 10.1002/art.40785

74. Koga T, Ichinose K, Mizui M, Crispin JC, Tsokos GC. Calcium/calmodulindependent protein kinase IV suppresses IL-2 production and regulatory T cell activity in lupus. J Immunol. 2012;189(7):3490-6. doi: 10.4049/jimmunol.1201785

75. Juang YT, Wang Y, Solomou EE, Li Y, Mawrin C, Tenbrock K, et al. Systemic lupus erythematosus serum IgG increases CREM binding to the IL-2 promoter and suppresses IL-2 production through CaMKIV. J Clin Invest. 2005;115(4):996-1005. doi: 10.1172/JCI22854 
76. Ichinose K, Juang YT, Crispin JC, Kis-Toth K, Tsokos GC. Suppression of autoimmunity and organ pathology in lupus-prone mice upon inhibition of calcium/calmodulin-dependent protein kinase type IV. Arthritis Rheum. 2011;63(2):523-9. doi: 10.1002/art.30085

77. Maeda K, Otomo K, Yoshida N, Abu-Asab MS, Ichinose K, Nishino T, et al. CaMK4 compromises podocyte function in autoimmune and nonautoimmune kidney disease. J Clin Invest. 2018;128(8):3445-59. doi: 10.1172/JCI99507

78. Koga T, Hedrich CM, Mizui M, Yoshida N, Otomo K, Lieberman LA, et al. CaMK4-dependent activation of AKT/mTOR and CREM-alpha underlies autoimmunity-associated Th17 imbalance. J Clin Invest. 2014;124(5):2234-45. doi: 10.1172/JCI73411

79. Kono M, Maeda K, Stocton-Gavanescu I, Pan W, Umeda M, Katsuyama E, et al. Pyruvate kinase M2 is requisite for Th1 and Th17 differentiation. JCI Insight. 2019;4(12): e127395. doi: 10.1172/jci.insight.127395

80. Kono M, Yoshida N, Maeda K, Skinner NE, Pan W, Kyttaris VC, et al. Pyruvate dehydrogenase phosphatase catalytic subunit 2 limits Th17 differentiation. Proc Natl Acad Sci U S A. 2018;115(37):9288-93. doi: 10.1073/pnas.1805717115

81. Foulkes NS, Sassone-Corsi P. More is better: activators and repressors from the same gene. Cell. 1992;68(3):411-4.

82. Yoshida N, Comte D, Mizui M, Otomo K, Rosetti F, Mayadas TN, et al. ICER is requisite for Th17 differentiation. Nat Commun. 2016;7:12993. doi: 10.1038/ncomms12993

83. Choi SC, Titov AA, Abboud G, Seay HR, Brusko TM, Roopenian DC, et al. Inhibition of glucose metabolism selectively targets autoreactive follicular helper T cells. Nat Commun. 2018;9(1):4369. doi: 10.1038/s41467-018-06686-0

84. Pavon EJ, Zumaquero E, Rosal-Vela A, Khoo KM, Cerezo-Wallis D, GarciaRodriguez S, et al. Increased CD38 expression in T cells and circulating antiCD38 IgG autoantibodies differentially correlate with distinct cytokine profiles and disease activity in systemic lupus erythematosus patients. Cytokine. 2013;62(2):232-43. doi: 10.1016/j.cyto.2013.02.023

85. Bradley SJ, Suarez-Fueyo A, Moss DR, Kyttaris VC, Tsokos GC. T Cell Transcriptomes Describe Patient Subtypes in Systemic Lupus Erythematosus. PLoS One. 2015;10(11):e0141171. doi: 10.1371/journal.pone.0141171

86. Chatterjee S, Daenthanasanmak A, Chakraborty P, Wyatt MW, Dhar P, Selvam SP, et al. CD38-NAD(+)Axis Regulates Immunotherapeutic Anti-Tumor T Cell Response. Cell Metab. 2018;27(1):85-100.e8. doi: 10.1016/j.cmet.2017.10.006

87. Katsuyama E, Suarez-Fueyo A, Bradley SJ, Mizui M, Marin AV, Mulki L, et al. The CD38/NAD/SIRTUIN1/EZH2 Axis Mitigates Cytotoxic CD8 T Cell Function and Identifies Patients with SLE Prone to Infections. Cell Rep. 2020;30(1):11223.e4. doi: 10.1016/j.celrep.2019.12.014

88. Kono M, Yoshida N, Maeda K, Tsokos GC. Transcriptional factor ICER promotes glutaminolysis and the generation of Th17 cells. Proc Natl Acad Sci U S A. 2018;115(10):2478-83. doi: 10.1073/pnas.1714717115

89. Chapman NM, Boothby MR, Chi H. Metabolic coordination of T cell quiescence and activation. Nat Rev Immunol. 2019. doi: 10.1038/s41577-019-0203-y 
90. Lian G, Gnanaprakasam JR, Wang T, Wu R, Chen X, Liu L, et al. Glutathione de novo synthesis but not recycling process coordinates with glutamine catabolism to control redox homeostasis and directs murine $\mathrm{T}$ cell differentiation. Elife. 2018;7. doi: 10.7554/eLife.36158

91. Nakaya M, Xiao Y, Zhou X, Chang JH, Chang M, Cheng X, et al. Inflammatory T cell responses rely on amino acid transporter ASCT2 facilitation of glutamine uptake and mTORC1 kinase activation. Immunity. 2014;40(5):692-705. doi: 10.1016/j.immuni.2014.04.007

92. Johnson MO, Wolf MM, Madden MZ, Andrejeva G, Sugiura A, Contreras DC, et al. Distinct Regulation of Th17 and Th1 Cell Differentiation by GlutaminaseDependent Metabolism. Cell. 2018;175(7):1780-95.e19. doi: 10.1016/j.cell.2018.10.001

93. Kono M, Yoshida N, Maeda K, Suarez-Fueyo A, Kyttaris VC, Tsokos GC. Glutaminase 1 Inhibition Reduces Glycolysis and Ameliorates Lupus-like Disease in MRL/lpr Mice and Experimental Autoimmune Encephalomyelitis. Arthritis Rheumatol. 2019. doi: 10.1002/art.41019

94. Xu T, Stewart KM, Wang X, Liu K, Xie M, Kyu Ryu J, et al. Metabolic control of TH17 and induced Treg cell balance by an epigenetic mechanism. Nature. 2017 Aug 10;548(7666):228-233. doi: 10.1038/nature23475

95. Michalek RD, Gerriets VA, Nichols AG, Inoue M, Kazmin D, Chang CY, et al. Estrogen-related receptor-alpha is a metabolic regulator of effector T-cell activation and differentiation. Proc Natl Acad Sci U S A. 2011;108(45):1834853. doi: 10.1073/pnas.1108856108

96. Ma EH, Poffenberger MC, Wong AH, Jones RG. The role of AMPK in T cell metabolism and function. Curr Opin Immunol. 2017;46:45-52. doi: 10.1016/j.coi.2017.04.004

97. Kono M, Yoshida N, Tsokos GC. Metabolic control of T cells in autoimmunity. Curr Opin Rheumatol. 2019. doi: 10.1097/BOR.0000000000000685

98. Procaccini C, Carbone F, Di Silvestre D, Brambilla F, De Rosa V, Galgani M, et al. The Proteomic Landscape of Human Ex Vivo Regulatory and Conventional T Cells Reveals Specific Metabolic Requirements. Immunity. 2016;44(2):40621. doi: 10.1016/j.immuni.2016.01.028

99. Endo Y, Asou HK, Matsugae N, Hirahara K, Shinoda K, Tumes DJ, et al. Obesity Drives Th17 Cell Differentiation by Inducing the Lipid Metabolic Kinase, ACC1. Cell Rep. 2015;12(6):1042-55. doi: 10.1016/j.celrep.2015.07.014

100. Ricciardi S, Manfrini N, Alfieri R, Calamita P, Crosti MC, Gallo S, et al. The Translational Machinery of Human CD4(+) T Cells Is Poised for Activation and Controls the Switch from Quiescence to Metabolic Remodeling. Cell Metab. 2018;28(6):961. doi: 10.1016/j.cmet.2018.09.010

101. Zhang X, Tao Y, Troiani L, Markovic-Plese S. Simvastatin inhibits IFN regulatory factor 4 expression and Th17 cell differentiation in CD4+ T cells derived from patients with multiple sclerosis. J Immunol. 2011;187(6):3431-7. doi: 10.4049/jimmunol.1100580

102. McDonald G, Deepak S, Miguel L, Hall CJ, Isenberg DA, Magee AI, et al. Normalizing glycosphingolipids restores function in CD4+ T cells from lupus patients. J Clin Invest. 2014;124(2):712-24. doi: 10.1172/JCI69571 
103. Sawaf M, Fauny JD, Felten R, Sagez F, Gottenberg JE, Dumortier H, et al. Defective BTLA functionality is rescued by restoring lipid metabolism in lupus CD4+ T cells. JCI Insight. 2018;3(13):e99711. doi: 10.1172/jci.insight.99711

104. Nowling TK, Fulton JD, Chike-Harris K, Gilkeson GS. Ets factors and a newly identified polymorphism regulate Fli1 promoter activity in lymphocytes. Mol Immunol. 2008;45(1):1-12. doi: 10.1016/j.molimm.2007.05.018

105. Zhang L, Eddy A, Teng YT, Fritzler M, Kluppel M, Melet F, et al. An immunological renal disease in transgenic mice that overexpress Fli-1, a member of the ets family of transcription factor genes. Mol Cell Biol. 1995;15(12):6961-70. doi: 10.1128/mcb.15.12.6961

106. Richard EM, Thiyagarajan T, Bunni MA, Basher F, Roddy PO, Siskind LJ, et al. Reducing FLI1 levels in the MRL/lpr lupus mouse model impacts $\mathrm{T}$ cell function by modulating glycosphingolipid metabolism. PLoS One. 2013;8(9):e75175. doi: 10.1371/journal.pone.0075175

How to cite this article:

Vukelic M, Kono M, Tsokos GC. T cell Metabolism in Lupus. Immunometabolism. 2020;2(2):e200009. https://doi.org/10.20900/immunometab20200009 